\title{
A Rent Extraction Theory of Right of First Refusal*
}

\author{
Albert H. Choi \\ Department of Economics \\ University of Virginia
}

July 31, 2003

\begin{abstract}
When a seller gives a buyer a right of first refusal, although it reduces the competing buyers' profits and creates an inefficiency, it always increases the joint profit of the seller and the right holder. Right of first refusal with a consideration (e.g., a payment from the right holder to the seller) allows the seller and the right holder to extract more surplus from the competing buyers.
\end{abstract}

JEL codes: D44, K12, K22

\section{Introduction}

Suppose in the midst of a lease negotiations between a property-owner and a prospective tenant, the tenant asks for a right of first refusal on the owner's property for the lease term. If the owner agrees to the tenant's proposal, whenever a third party makes an offer to buy the owner's property and the owner decides to sell, before accepting the third party's offer, the owner must first give the tenant the opportunity to match the third party's offer and purchase the property. On its first impression, the right confers the tenant a leverage in acquiring the owner's property by being able to observe the third party's offer without revealing his own value for the property. At the same time, it puts the owner at a disadvantage by not being to induce a more competitive bidding between the tenant and the third party, ${ }^{1}$ and robs the third party an opportunity to compete more on an equal footing against the tenant.

Regardless of this seeming bias, the usage of right of first refusal is wide-spread: it is visible not only in lease transactions, but also in joint ventures, corporate securities, oil and gas transactions, employment, broadcasting agreements and contracts involving various commercial products. ${ }^{2}$ The most frequently offered justification seems to be that the right minimizes the undesirable possibility of the right holder's facing a new, hostile partner in the

${ }^{*}$ Acknowledgments to be added. Comments are welcome to Albert Choi, Department of Economics, University of Virginia, PO Box 400182, Rouss Hall 114, Charlottesville, VA 22904-4182 or ahc4p@virginia.edu. 
relationship. When the value from the relationship is sensitive to the identify of the partner, the right allows the right holder to preempt the possibility of an incompatible partner (and a lower value from the relationship) by buying out the entire property. For instance, in the close corporation context, some argue that adopting a right of first refusal provides the shareholders the leverage in being able to choose the future partners in the transaction and thereby preserve the value of the firm. ${ }^{3}$ In accordance, the courts have upheld its legality as being a "reasonable" restriction on the transferability of the encumbered property. ${ }^{4}$

However, the assumption that the value of the relationship is sensitive to the identity of the partner also implies that the right holder is likely to place a higher value on the property than the third party. In the landlord-tenant setting, because the tenant's value of the lease is lower when the property is sold to an inhospitable third party, holding everything else constant, the tenant would be willing to pay more for the property than the third party. Even if a competitive sale process takes place, the tenant is more likely to acquire the property anyway, so that granting the right to the tenant seems to over-protect the tenant, while possibly reducing the owner's return from the sale. Furthermore, the right is often used in transactions, such as oil and gas and commercial products, where the identitysensitivity is absent or, at best, minimal. The traditional justification seems to lack power in explaining the wide-spread use of the right when preserving the identity of the business partner is either unnecessary or unimportant.

We attempt to provide a more systematic analysis of the right of first refusal. By casting the right as an auction process, we can explicitly analyze the behaviors of the tenant, the owner, and the third party, and answer questions such as whether the involved parties will indeed be better or worse off with the right, and what incentive the owner and the tenant will have in inserting this clause in their contract. In a private value setting with two bidders $\left(B_{1}\right.$ and $\left.B_{2}\right)$ and one seller $(S)$, we treat the right of first refusal as granting one of the bidders $\left(B_{1}\right)$ the right to observe the other's $\left(B_{2}\right.$ 's) bid before making his own. When $B_{1}$ has the right, $B_{2}$ first makes an offer, and $B_{1}$ can either match $B_{2}$ 's offer or let $B_{2}$ win the auction after observing $B_{2}$ 's offer. We compare the results from the right of first refusal to those from the four "standard" auctions: first-price-sealed-bid, second-price-sealed-bid, English, and Dutch auctions.

Allowing $B_{1}$ to make such a conditional offer reduces $B_{2}$ 's expected profits and produces an inefficiency. Because $B_{2}$ bids below his value $\left(b_{2}<v_{2}\right), B_{1}$ can win the auction even when his value is lower than $B_{2}$ 's $\left(b_{2}<v_{1}<v_{2}\right)$, hence reducing $B_{2}$ 's chances of winning and allocating the property to the bidder with a lower value. On the other hand, the right has an ambiguous effect on $B_{1}$ 's and the seller's stand-alone profits. When the buyers' values are positively correlated, $B_{1}$ 's profit is higher in the first price auction than in the English auction. In the English auction, the winning bidder's payment is equal to the losing bidder's value, so if $B_{1}$ wins, $B_{1}$ 's payment is equal to $v_{2}$. In contrast, when $B_{1}$ has the right of first refusal, since he would never pay more than $b_{2}, B_{1}$ 's winning bid is less than $v_{2}$, hence yielding a higher profit. When $B_{2}$ becomes very aggressive $\left(b_{2} \rightarrow v_{2}\right)$, 
however, $B_{1}$ 's profit may only be slightly higher than in the English auction, but insufficient to surpass the profit from the first price auction. For the seller, $B_{2}$ becoming aggressive raises the seller's profit to the point that, in the extreme, the seller may be able to extract close to the entire surplus of $B_{2}$, whereas this is never possible in the standard auctions.

Most importantly, the expected joint profit of the seller and the right-holder $\left(S\right.$ and $\left.B_{1}\right)$ will always be higher with the right than in the standard auctions. Suppose the seller's value of the property is zero, and the seller can choose between the English auction and the right of first refusal. In the English auction, since the winning bidder's payment is equal to the losing bidder's value, regardless of who wins the auction, the joint profit of the seller and the right-holder $\left(S\right.$ and $\left.B_{1}\right)$ is equal to the right-holder's value $\left(v_{1}\right)$. With the right, however, $B_{2}$ can win the auction only when his bid is above the right-holder's value $\left(b_{2}>v_{1}\right)$, since otherwise, $B_{1}$ will match the bid and obtain the property. So, while $B_{1}$ 's winning produces the joint profit that is equal to the right-holder's value $\left(v_{1}\right), B_{2}$ 's winning produces the profit that is strictly higher than $B_{1}$ 's value $\left(b_{2}>v_{1}\right)$, thus, yielding a higher joint profit for the seller and the right-holder.

The higher joint profit provides an incentive for the seller to "sell" the right to $B_{1}$ for an adequate consideration. In the landlord-tenant setting, for instance, if the right does reduce the owner's expected return from her future sale, as a contractual consideration, the owner can demand a higher lease payment. Similarly, in a joint venture setting, the partners can exchange rights of first refusal on their ownership shares as considerations. While giving the right to the other partner reduces the third party's expected profit from bidding for the partner's share in the future, it provides a positive benefit for both partners. In a sense, the right of first refusal functions as an explicit, court-endorsed collusion mechanism between the buyer and the seller against future buyers. ${ }^{5}$ It extracts rent from future buyers with relatively high values, while prohibiting lower-valued buyers from purchasing the property: it functions as a contractual barrier to entry. ${ }^{6}$

The paper is organized as follows. In the next section, we provide an illustrative example with a uniform distribution with independent values that is sufficiently rich to explain the main ideas but with minimal analytics. In the following section, we demonstrate the result with a more general distribution. We compare the right of first refusal case to the four standard auctions and explain why the right-holder's and the seller's stand-alone profits can be either higher or lower with the right but why the joint profit of the seller and the right-holder is always higher. The last section concludes with thoughts for future research.

\section{An Illustrative Example}

Suppose we have two buyers $\left(B_{1}\right.$ and $\left.B_{2}\right)$ and a seller $(S)$, who are all risk neutral. The seller has the reservation value of zero $\left(v_{s}=0\right)$, while the buyers' values $\left(v_{1}\right.$ and $\left.v_{2}\right)$ are independently and uniformly distributed between 0 and 1 . The seller can run either a 
first-price-sealed-bid auction, or grant a right of first refusal to the first buyer $\left(B_{1}\right)$. If $B_{1}$ has the right, $B_{1}$ makes a bid $\left(b_{1}^{r}\right)$ only after observing $B_{2}$ 's bid $\left(b_{2}^{r}\right)$. In the real world, conditional on the seller deciding to sell the property, the right obligates the seller to reveal a third party's offer $\left(b_{2}^{r}\right)$ to the right holder and given the right holder the option to match the third party's bid. So, our setting is analytically similar. In contrast, in the first-pricesealed-bid auction, both buyers simultaneously make their bids $\left(b_{1}^{f}\right.$ and $\left.b_{2}^{f}\right)$. Receiving a third party offer does not obligate the seller to reveal that offer to the inside buyer, so the inside buyer $\left(B_{1}\right)$ must compete against the third party $\left(B_{2}\right)$ without knowing the nature of the third party's offer $\left(b_{2}^{r}\right)$.

\subsection{First Price Sealed Bid Auction}

With the independent, uniform distribution, each buyer's bid is equal to one-half of his own value, $b_{i}^{f}\left(v_{i}\right)=\frac{v_{i}}{2}$, and given the symmetry, a buyer will win only when he values the property more than the competitor $\left(v_{i}>v_{j}\right)$. Conditional on a buyer's value $\left(v_{i}\right)$, his expected profit is the probability that the competing buyer's value is less than his, $p\left(v_{j}<v_{i}\right)$, multiplied by his profit margin, $v_{i}-b_{i}^{f}=\frac{v_{i}}{2}$. In the current example, this probability is equal to $v_{i}$, so that his conditional expected profit is $\frac{v_{i}^{2}}{2}$. Each buyer's unconditional expected profit is, in turn, given by

$$
E\left(\pi_{1}^{f}\right)=E\left(\pi_{2}^{f}\right)=\int_{v_{i}=0}^{1} \frac{v_{i}^{2}}{2} d v_{i}=\frac{1}{6} .
$$

The seller's unconditional expected profit is found by adding both buyers' expected payments:

$$
\begin{aligned}
E\left(\pi_{s}^{f}\right) & =E\left(B_{1}^{\prime} s \text { payment }\right)+E\left(B_{2}^{\prime} \text { s payment }\right) \\
& =2 \int_{v_{1}=0}^{1} b_{1}^{f} \operatorname{prob}\left(v_{2}<v_{1}\right) d v_{1}=2 \int_{v_{1}=0}^{1} v_{1} \frac{v_{1}}{2} d v_{1}=\frac{1}{3}
\end{aligned}
$$

Finally, the expected joint profit of $B_{1}$ and the seller is equal to $B_{1}$ 's unconditional expected value $\left(E\left(v_{1}\right)\right): E\left(\pi_{s}^{f}\right)+E\left(\pi_{1}^{f}\right)=\frac{1}{6}+\frac{1}{3}=\frac{1}{2}$. The expected social welfare, given by the sum of all three parties' profits, is

$$
E\left(S W^{f}\right)=E\left(\pi_{1}^{f}\right)+E\left(\pi_{2}^{f}\right)+E\left(\pi_{s}^{f}\right)=\frac{2}{3} .
$$




\section{$2.2 \quad$ Right of First Refusal}

Let's first solve for the buyers' optimal bidding strategies: $b_{i}^{r}\left(v_{i}\right)$. Since $B_{1}$ observes $b_{2}^{r}$ before making his own bid, $B_{1}$ will match $b_{2}^{r}$ if $b_{2}^{r}$ is less than $v_{1}$, and drop out (or bid zero) if $b_{2}^{r}$ is larger than $v_{1}$ :

$$
b_{1}^{r}\left(v_{1}\right)=\left\{\begin{array}{cl}
b_{2}^{r} & \text { if } b_{2}^{r} \leq v_{1} \\
0 & \text { if } b_{2}^{r}>v_{1}
\end{array}\right.
$$

For $B_{2}$, because he has to bid more than $v_{1}$ to win the auction, $B_{2}$ 's conditional profit is

$$
E\left(\pi_{2}^{r}\left(b_{2}^{r}\right) \mid v_{2}\right)=\operatorname{prob}\left(b_{2}^{r}>v_{1}\right)\left(v_{2}-b_{2}^{r}\right)=b_{2}^{r}\left(v_{2}-b_{2}^{r}\right) .
$$

$B_{2}$ will choose $b_{2}^{r}$ to maximize this profit, i.e., $\frac{d E\left(\pi_{2}^{r}\left(b_{2}^{r}\right) \mid v_{2}\right)}{d b_{2}^{r}}=0$, so that $b_{2}^{r}=\frac{v_{2}}{2}$ and $E\left(\pi_{2}^{r} \mid v_{2}\right)=\frac{v_{2}}{2}\left(v_{2}-\frac{v_{2}}{2}\right)=\frac{v_{2}^{2}}{4}$. Note that $B_{2}$ adopts the same strategy as in the first price auction. Therefore, while his profit margin is the same as in the first price auction $\left(\frac{v_{2}}{2}\right)$, the probability of winning is lower (from $v_{2}$ to $\frac{v_{2}}{2}$ ). To find $B_{2}$ 's unconditional expected profit,

$$
E\left(\pi_{2}^{r}\right)=\int_{v_{2}=0}^{1} \frac{v_{2}^{2}}{4} d v_{2}=\frac{1}{4} \int_{v_{2}=0}^{1} v_{2}^{2} d v_{2}=\frac{1}{12} .
$$

Compared to the first price auction, $B_{2}$ 's expected profit is lower by $\frac{1}{12}$.

For $B_{1}$, we need to examine two separate cases. First, given $b_{2}^{r}=\frac{v_{2}}{2}, B_{2}$ 's highest bid is $\frac{1}{2}$. So, whenever $v_{1}>\frac{1}{2}, B_{1}$ will obtain the good with certainty while expecting to pay $b_{2}^{r}$. Hence,

$$
E\left(\pi_{1}^{r} \mid v_{1}>\frac{1}{2}\right)=\left(v_{1}-E\left(b_{2}^{r}\right)\right)=v_{1}-\frac{1}{4} .
$$

Second, when $v_{1}<\frac{1}{2}, B_{1}$ 's conditional profit is equal to $\operatorname{prob}\left(b_{2}^{r}<v_{1}\right)$ multiplied by his expected profit margin, which is $v_{1}$ minus $B_{2}$ 's expected bid conditional on $B_{2}$ 's bid being less than $v_{1}$, i.e., $\left(v_{1}-E\left(b_{2}^{r} \mid b_{2}^{r}<v_{1}\right)\right)$. In notation,

$$
\begin{aligned}
E\left(\pi_{1}^{r} \mid v_{1}\right. & \left.<\frac{1}{2}\right)=p\left(b_{2}^{r}<v_{1}\right)\left(v_{1}-E\left(b_{2}^{r} \mid b_{2}^{r}<v_{1}\right)\right) \\
& =p\left(\frac{v_{2}}{2}<v_{1}\right)\left(v_{1}-\frac{v_{1}}{2}\right)=2 v_{1} \frac{v_{1}}{2}=v_{1}^{2}
\end{aligned}
$$

Combining these two results,

$$
E\left(\pi_{1}^{r}\right)=\int_{v_{1}=0}^{1 / 2} v_{1}^{2} d v_{1}+\int_{v_{1}=1 / 2}^{1}\left(v_{1}-\frac{1}{4}\right) d v_{1}=\frac{7}{24} .
$$


Compared to the first price auction, $B_{1}$ 's expected profit is higher by $\frac{1}{8}$.

The seller's expected profit can be derived by adding both buyers' expected payments. $B_{2}$ 's expected payment is

$$
E\left(B_{2}^{\prime} s \text { payment }\right)=\int_{v_{2}=0}^{1} \operatorname{prob}\left(b_{2}^{r}>v_{1}\right) b_{2}^{r} d v_{2}=\int_{v_{2}=0}^{1} \frac{v_{2}}{2} \frac{v_{2}}{2} d v_{2}=\frac{1}{12},
$$

and $B_{1}$ 's,

$$
\begin{aligned}
E\left(B_{1}^{\prime} s \text { payment }\right) & =\int_{v_{1}=0}^{1 / 2} \operatorname{prob}\left(b_{2}^{r}<v_{1}\right) E\left(b_{2}^{r} \mid b_{2}^{r}<v_{1}\right) d v_{1}+\int_{v_{1}=1 / 2}^{1} E\left(b_{2}^{r}\right) d v_{1} \\
& =\int_{v_{1}=0}^{1 / 2} 2 v_{1} \frac{v_{1}}{2} d v_{1}+\int_{v_{1}=1 / 2}^{1} \frac{1}{4} d v_{1}=\frac{1}{6},
\end{aligned}
$$

so that

$$
E\left(\pi_{s}^{r}\right)=\frac{1}{12}+\frac{1}{6}=\frac{1}{4}
$$

Compared to the first price auction, the seller's profit is lower by $\frac{1}{12}$. The expected social welfare is

$$
E\left(S W^{r}\right)=E\left(\pi_{1}^{r}\right)+E\left(\pi_{2}^{r}\right)+E\left(\pi_{s}^{r}\right)=\frac{15}{24} .
$$

The right of first refusal generates a welfare loss of $\frac{1}{24}$. However, the expected joint profit of $B_{1}$ and the seller is $E\left(\pi_{s}^{r}\right)+E\left(\pi_{1}^{r}\right)=\frac{1}{4}+\frac{7}{24}=\frac{13}{24}$, which is higher than in the first price auction by $\frac{1}{24}$.

\subsection{The Joint Profit of the First Buyer and the Seller}

The reason the right of first refusal increases the joint profit stems from the fact that when $B_{1}$ has the right, $B_{2}$ must bid above $B_{1}$ 's value $\left(b_{2}^{r}>v_{1}\right)$ to win the competition, whereas, in the first price auction, $B_{2}$ only has to bid above $B_{1}$ 's bid $\left(b_{2}^{f}>b_{1}^{f}\right)$ to win. Regardless of the auction type, we know that $B_{1}$ 's winning produces the joint profit that is equal to $v_{1}$, so the source of difference in the joint profit lies in how much $B_{2}$ pays when $B_{2}$ wins the auction. In the first price auction, $B_{2}$ is able to obtain the property whenever $B_{2}$ values the property more than $B_{1}$, and, when he wins, he only has to pay $v_{1}$. Once $B_{1}$ is allowed to observe $B_{2}$ 's bid through the right of first refusal, however, because $B_{2}$ has to pay more than $v_{1}$ to win, $B_{2}$ 's winning produces a profit of $b_{2}^{r}$ which is higher than $v_{1}$. Although 
the probability that $B_{2}$ will win is lower than in the first price auction, so long as that probability is positive, the right produces a higher expected joint profit for the seller and the right holder.

To better illustrate, suppose $v_{2}$ is fixed at $\frac{1}{2}$ and $v_{1}$ is distributed uniformly between 0 and 1. If the seller uses the first price auction, $b_{2}^{f}=\frac{1}{4}$ and $b_{1}^{f}=\frac{v_{1}}{2}$, as shown above. So, $B_{1}$ wins the auction when $v_{1} \geq \frac{1}{2}\left(b_{1}^{f} \geq b_{2}^{f}\right)$, and when $B_{1}$ wins, the joint profit of $B_{1}$ and the seller is equal to $v_{1}\left(\pi_{1}^{f}+\pi_{s}^{f}=\left(v_{1}-\frac{v_{1}}{2}\right)+\left(v_{1}-0\right)=v_{1}\right)$. When $B_{2}$ wins, which happens when $v_{1}<\frac{1}{2}$, the joint profit is equal to $B_{2}$ 's bid, which is $\frac{1}{4}\left(\pi_{1}^{f}+\pi_{s}^{f}=0+\left(\frac{1}{4}-0\right)=\frac{1}{4}\right)$. But, this is equal to $B_{1}$ 's expected value conditional on losing, i.e., $E\left(v_{1} \mid v_{1}<\frac{1}{2}\right)$. Therefore, regardless of the identity of the winner, the expected joint profit of $B_{1}$ and the seller is equal to $v_{1}$.

Now, suppose $B_{1}$ has the right of first refusal. While $B_{2}$ bids $\frac{1}{4}$ as before, because $B_{1}$ gets to observe $B_{2}$ 's bid, $B_{1}$ wins whenever $v_{1} \geq \frac{1}{4}$. While $B_{1}$ 's probability of winning is higher, when $B_{1}$ wins, the joint profit of the seller and the first buyer is still equal to $v_{1}\left(\pi_{1}^{r}+\pi_{s}^{r}=\left(v_{1}-\frac{1}{4}\right)+\left(\frac{1}{4}-0\right)=v_{1}\right)$. The difference kicks in when $B_{1}$ loses. When $v_{1}<\frac{1}{4}$, the joint profit of the seller and $B_{1}$ is equal to the second buyer's bid of $\frac{1}{4}$ $\left(\pi_{1}^{r}+\pi_{s}^{r}=0+\left(\frac{1}{4}-0\right)=\frac{1}{4}\right)$. In contrast to the first price auction, this joint profit is higher than $B_{1}$ 's expected value for the good $\left(E\left(v_{1} \mid v_{1}<\frac{1}{4}\right)=\frac{1}{8}\right)$ by the virtue of the fact that $B_{2}$ has to outbid $B_{1}$ 's value. Hence, even when $B_{1}$ loses, $B_{1}$ and the seller realize a joint profit that is higher than $B_{1}$ 's value. The right "forces" $B_{2}$ to outbid $B_{1}$ 's value to win and enables the seller and $B_{1}$ to extract more surplus from $B_{2}$, while generating a welfare loss in the process.

In this example with uniform, independent distributions, the seller's stand-alone profit always decreases with the right while the right-holder's profit always increases. Although this may seem intuitive, we show that this won't always be the case. First, since the buyers are competing for the same good, it is quite plausible that their values are positively correlated: independence no longer holds. In that case, the buyers' and the seller's profits are sensitive to which type of standard auction is selected, and this may, in turn, produce different relative profit ranking when compared to the right of first refusal. Second, what is unique about the uniform distribution is that the second buyer's strategy is independent of whether or not the first buyer has the right of first refusal. Under other types of distributions, the second buyer can become more or less aggressive (compared to the standard auctions), and this will also produce different profits for both the seller and the right holder. Since neither the uniformity nor the independence assumptions are realistic, we relax them in the next section and produce the more general results. 


\section{The Model}

There are three risk-neutral, profit-maximizing players with a single good. A seller $(S)$ has the good with the reservation value of zero. An inside buyer $\left(B_{1}\right)$, whose value of the good is $v_{1}$, can be given the right of first refusal. An outside bidder $\left(B_{2}\right)$ competes against the inside buyer and values the good at $v_{2}$. We assume that $v_{1}$ and $v_{2}$ are unknown, ex ante, but have a joint distribution over the support of $[0, \bar{v}]^{2}$ with a strictly positive, differentiable density of $f\left(v_{1}, v_{2}\right) .{ }^{7} \quad$ We assume that $f\left(v_{1}, v_{2}\right)$ satisfies the monotone likelihood ratio property (MLRP), i.e., $\frac{\partial^{2}}{\partial v_{1} \partial v_{2}} \ln \left(f\left(v_{1}, v_{2}\right)\right) \geq 0 .{ }^{8}$ The assumption implies that if one buyer values the good highly, the other buyer is also likely to value the good highly. ${ }^{9}$ It allows the possibility of commonality in the values of the property. If the condition is satisfied with equality, the values are independent.

The timing of the game is as follows. We assume that there is no time discount. First, the seller decides whether to grant a right of first refusal to the first buyer $\left(B_{1}\right)$ and announces her decision to the buyers. We assume that if the seller grants the right to the first buyer, $B_{1}$ pays the seller as a consideration, ${ }^{10}$ and if the seller does not grant the right, the seller chooses one of four standard auctions: English, Dutch, first-price-sealed-bid, or second-price-sealed-bid. Second, the buyers privately and costlessly observe their values. ${ }^{11}$ Third, the selected auction is run and the property is sold to the highest bidder. If the first buyer $\left(B_{1}\right)$ has the right of first refusal, the second buyer $\left(B_{2}\right)$ first makes a bid, and the first buyer makes a competing bid, after observing the second buyer's bid. If, for instance, the first-price-sealed-bid auction is run, both buyers simultaneously submit their bids.

\subsection{Standard Auctions}

In the standard auctions, the bidder with a higher value wins the auction. In either the English or the second price auctions, it is each player's dominant strategy to either stay in the auction until the ascending price reaches to the bidder's value or bid his own value, so that the winning bidder's payment is equal to the losing bidder's value. In the first price or the Dutch auctions, the winning bidder's payment is equal to the price the bidder stops the descending price at or the bid the bidder makes. Since the bidding behavior will be sensitive to the beliefs the bidder has about the other's behavior, we assume symmetry in bidding strategies and find the symmetric Bayesian Nash equilibrium. The derivations are shown in the appendix.

The expected profits of all three players will be equal in the English and the second price auctions, and in the first price and the Dutch auctions. Denote the players' expected profits in the English and the second price auctions as $E\left(\pi_{i}^{e}\right)$ and their profits in the first price and the Dutch auctions as $E\left(\pi_{i}^{f}\right)$ where $i \in\{1,2, s\}$. As well known in the literature, the monotone likelihood ratio property of the density function implies that the seller's expected profit will be (weakly) higher in the English or the second price auctions than in the first 
price or the Dutch auctions $\left(E\left(\pi_{s}^{e}\right) \geq E\left(\pi_{s}^{f}\right)\right)$. Conversely, the buyers' expected profits in the English and the second price auctions will be (weakly) higher than in the other two auctions $\left(E\left(\pi_{i}^{e}\right) \leq E\left(\pi_{i}^{f}\right)\right.$ for $\left.i \in\{1,2\}\right)$. If we examine the joint expected profit of the seller and the first buyer $\left(B_{1}\right)$, we obtain the following result.

Lemma 1 In the standard auctions, the expected joint profit of the first buyer and the seller is not higher than the unconditional expected value of the first buyer:

$$
E\left(\pi_{s}^{f}\right)+E\left(\pi_{1}^{f}\right) \leq E\left(\pi_{s}^{e}\right)+E\left(\pi_{1}^{e}\right)=E\left(v_{1}\right) .
$$

Consider the English or the second price auction. If the first buyer wins, the joint profit is equal to $v_{1}\left(\pi_{1}^{e}+\pi_{s}^{e}=v_{1}-b_{1}+b_{1}-0\right)$. Even when the second buyer wins, since the second buyer only pays $v_{1}$, the joint profit is, again, equal to $v_{1}\left(\pi_{1}^{e}+\pi_{s}^{e}=v_{1}-0\right)$. Hence, the ex ante joint profit is equal to the unconditional expected value of the first buyer. Similarly, in the first price or the Dutch auctions, the first buyer's winning produces the joint profit equal to $v_{1}\left(\pi_{1}^{f}+\pi_{s}^{f}=v_{1}-b_{1}+b_{1}-0\right)$. However, when the second buyer wins, the monotone likelihood ratio property implies that the second buyer's payment is (weakly) less than the first buyer's value $\left(b_{2}^{f} \leq v_{1}\right)$, so that the joint profit of the first buyer and the seller is less than $v_{1}\left(\pi_{1}^{f}+\pi_{s}^{f} \leq v_{1}\right)$. Therefore, the expected joint profit will be less than the unconditional expected value of the first buyer.

Since the seller, at best, receives the lower of the buyers' values as the winning bid, both buyers earn positive profits, and the seller cannot extract the full surplus from the either buyers. For instance, the seller's expected profit in the English auction is:

$$
E\left(\pi_{s}^{e}\right)=E\left(v_{2}\right)-\int_{v_{1}=0}^{\bar{v}} \int_{v_{2}=v_{1}}^{\bar{v}}\left(v_{2}-v_{1}\right) f\left(v_{1}, v_{2}\right) d v_{2} d v_{1}
$$

Since the first buyer's payment equals $v_{2}$ when the first buyer wins, the joint profit of the seller and the second buyer is also equal to the second buyer's unconditional expected valuation, $E\left(v_{2}\right)$, which is given by the first expression. The second expression denotes the expected profit (informational rent) that accrues to the second buyer: the expected difference between the winning bid $\left(v_{1}\right)$ and $v_{2}$.

\subsection{Right of First Refusal}

When the first buyer has the right of first refusal, the second buyer loses whenever his bid is less than the first buyer's value. If we let $b_{i}^{r}\left(v_{i}\right)$ to indicate buyer $i$ 's bidding strategy, $B_{1}$ 's optimal strategy is

$$
b_{1}^{r}\left(v_{1}\right)=\left\{\begin{array}{cl}
b_{2}^{r} & \text { if } b_{2}^{r} \leq v_{1} \\
0 & \text { if } b_{2}^{r}>v_{1}
\end{array}\right.
$$


For the second buyer, because the first buyer's optimal strategy depends on the second buyer's bid (as opposed to his value), closed-form solution, as in the standard auctions, cannot be found. Instead, the optimal strategy is implicitly defined.

Lemma 2 The second buyer's optimal bidding strategy is given by:

$$
b_{2}^{r}\left(v_{2}\right)=v_{2}-\frac{F_{1}\left(b_{2}^{r}\left(v_{2}\right) \mid v_{2}\right)}{f_{1}\left(b_{2}^{r}\left(v_{2}\right) \mid v_{2}\right)} .
$$

Due to the highly asymmetric bidding strategies between the buyers, we cannot guarantee that the second buyer's optimal bid will necessarily increase as his value increases. We leave open the possibility that $b_{2}^{r}\left(v_{2}\right)$ might actually be decreasing over some range. Furthermore, without making functional assumptions about the distribution, we cannot a priori determine how aggressive the second buyer will become when the first buyer has the right of first refusal, e.g., whether the bid will be higher than the bid made in the first price auction $\left(b_{2}^{f}\left(v_{2}\right) \lessgtr b_{2}^{r}\left(v_{2}\right)\right)$. What is important for our results is that the second buyer's optimal bid is less than his value for the good $\left(b_{2}^{r}\left(v_{2}\right) \leq v_{2}\right)$. This is evident from the lemma since the density is strictly positive $\left(f_{1}\left(b_{2}^{r}\left(v_{2}\right) \mid v_{2}\right)>0\right)$.

When the first buyer has the right of first refusal, the second buyer's expected profit will be strictly lower compared to the standard auctions. The right reduces both his chances of winning and the margin of profit. In the standard auctions, the second buyer won whenever his value is higher than the first buyer's $\left(v_{2} \geq v_{1}\right)$ and the second buyer's (expected) payment was equal or less than the first buyer's value $\left(b_{2}^{s} \leq v_{1}\right)$. In contrast, when the first buyer has the right, the second buyer can win when his bid is higher than the first buyer's value. Since his bid is lower than his value, this allows the first buyer to win the auction even when the first buyer's value is lower than the second buyer's: $B_{2}$ 's probability of winning is lower. Also, because the second buyer's winning bid is higher than the first buyer's value $\left(b_{2}^{r} \geq v_{1}\right)$, his profit margin is smaller compared to the standard auctions $\left(b_{2}^{r} \geq v_{1} \geq b_{2}^{s}\right)$.

For the first buyer, compared to the English or the second price auctions, he earns a bigger profit. In the English or the second price auctions, the first buyer pays the second buyer's value when he wins the auction $\left(b_{1}^{e}=v_{2}\right)$. With the right, because the first buyer only matches the second buyer's bid and the second buyer bids below his value $\left(b_{1}^{r}=b_{2}^{r}\left(v_{2}\right) \leq v_{2}\right)$, the first buyer's expected payment is lower and his profit is higher. However, when the right is compared to the first price or the Dutch auctions, since the first buyer's (expected) pay is already lower than the second buyer's value $\left(b_{1}^{f} \leq v_{2}\right)$, the profit ranking becomes ambiguous. If, for instance, the second buyer becomes very aggressive $\left(b_{2}^{r}\left(v_{2}\right) \rightarrow v_{2}\right)$ when the first buyer has the right, the first buyer's profit will only be slightly higher than in the English or the second price auctions, insufficient to outrank that in the first price or the Dutch auctions. 
Proposition 1 When the first buyer has a right of first refusal, the second buyer's expected profit is strictly lower than in the standard auctions:

$$
E\left(\pi_{2}^{r}\right)<E\left(\pi_{2}^{e}\right) \leq E\left(\pi_{2}^{f}\right)
$$

While the first buyer is better off compared to the English or the second price auctions, he may or may not be better off when compared to the first price or the Dutch auctions:

$$
E\left(\pi_{1}^{e}\right)<E\left(\pi_{1}^{r}\right) \gtreqless E\left(\pi_{1}^{f}\right) .
$$

To better understand the significance of the second buyer's strategy on the first buyer's expected profit, suppose, for the moment, that $B_{2}$ irrationally adopts the strategy of $b_{2}^{r}\left(v_{2}\right)=v_{2}$. Then, $B_{1}$ wins only when $v_{1}>v_{2}=b_{2}^{r}$, and when he wins, he pays $B_{2}$ 's value conditional on $B_{2}$ 's value being less than $v_{1}$. Therefore,

$$
\begin{aligned}
E\left(\pi_{1} \mid v_{1}\right) & =p\left(v_{1}>v_{2} \mid v_{1}\right)\left(v_{1}-E\left(v_{2} \mid v_{1}>v_{2}\right)\right) \\
& =F_{2}\left(v_{1} \mid v_{1}\right)\left(v_{1}-\int_{v_{2}=0}^{v_{1}} v_{2} \frac{f_{2}\left(v_{2} \mid v_{1}\right)}{F_{2}\left(v_{1} \mid v_{1}\right)} d v_{2}\right) .
\end{aligned}
$$

This is equal to the first buyer's profit when the English or the second price auctions is adopted. Since the first buyer's profit is higher with the first price or the Dutch auctions, $B_{2}$ being very aggressive can imply that the first buyer's profit is lower with the right than in the first price or the Dutch auctions.

Proposition 2 The seller's expected profit is equal to the expected value of the second buyer's bid:

$$
E\left(\pi_{s}^{r}\right)=E\left(b_{2}^{r}\left(v_{2}\right)\right)
$$

The seller can be either better or worse off than in the standard auctions:

$$
E\left(\pi_{s}^{r}\right) \lesseqgtr E\left(\pi_{s}^{k}\right) \text { where } k \in\{e, f\}
$$

Consider again the case where the second buyer is maximally aggressive: $b_{2}^{r}\left(v_{2}\right)=v_{2}$. Since the first buyer never pays more than the second buyer's bid, the seller earns the second buyer's expected value of the good: $E\left(\pi_{s}^{r}\right)=E\left(v_{2}\right)$. But, this is higher than the seller's profit in the four standard auctions, where her profit is always less than the expected value of the second buyer due to the second buyer's earning some information rent. Hence, the right of first refusal can increase the seller's profit. Conversely, if the second buyer becomes less, or even equally, aggressive $\left(b_{2}^{r}\left(v_{2}\right) \rightarrow 0\right)$ compared to the standard auctions, the seller's profit will be lower. This was the case in the example with the uniform, independent values. 
The reduction in social welfare from granting the right is given by

$$
E\left(S W^{k}\right)-E\left(S W^{r}\right)=\int_{v_{2}=0}^{\bar{v}} \int_{v_{1}=b_{2}^{r}\left(v_{2}\right)}^{v_{2}}\left(v_{2}-v_{1}\right) f\left(v_{1}, v_{2}\right) d v_{1} d v_{2}
$$

The right creates cases where the first buyer's value is lower than the second buyer's, but the good is allocated to the first buyer. This happens when $b_{2}^{r}\left(v_{2}\right)<v_{1}<v_{2}$, and the loss of welfare in that case is equal to $v_{2}-v_{1}$. Despite the lower social welfare, the joint profit of the first buyer and the seller will always be higher than in the standard auctions.

Proposition 3 The joint profit of the first buyer and the seller is higher when the seller grants the right of first refusal to the first buyer than when the seller runs one of the standard auctions:

$$
E\left(\pi_{s}^{r}\right)+E\left(\pi_{1}^{r}\right)>E\left(\pi_{s}^{k}\right)+E\left(\pi_{1}^{k}\right) \text { where } k \in\{e, f\}
$$

Figure 1 graphically summarizes the impact of the right of first refusal. To analyze the right's effect on the joint profit of the first buyer and the seller, consider three different cases. First, when the first buyer wins with a value higher than the second buyer's $\left(v_{1} \geq v_{2}\right)$, which corresponds to the area above the diagonal $\left(v_{1}=v_{2}\right)$, the first buyer and the seller realize the same joint profit as in the standard auctions: $\pi_{1}^{r}+\pi_{s}^{r}=v_{1}$. Second, when the first buyer wins but has a lower value than the second buyer, area below the diagonal but above $b_{2}^{r}\left(v_{2}\right)$, the right produces the joint profit of $v_{1}$, whereas the standard auctions yield the joint profit that is either equal to (English and second price) or less than (first price and Dutch) $v_{1}$. So, the right does at least as well as the standard auctions. Third, when the second buyer wins, which is below $b_{2}^{r}\left(v_{2}\right)$, because the second buyer is bidding more than $v_{1}$, the joint profit is strictly higher than $v_{1}$. Since the standard auctions, at best, produce the joint profit equal to $v_{1}$ in this region, the right of first refusal does strictly better.

The ex ante difference in the joint profits can be calculated by summing up the differences in the joint profits in the latter two regions.

$$
\int_{v_{2}=0}^{\bar{v}} \int_{v_{1}=b_{2}^{r}\left(v_{2}\right)}^{v_{2}}\left(v_{1}-b_{2}^{k}\left(v_{2}\right)\right) d F+\int_{v_{2}=0}^{\bar{v}} \int_{v_{1}=0}^{b_{2}^{r}\left(v_{2}\right)}\left(b_{2}^{r}\left(v_{2}\right)-v_{1}\right) d F>0
$$

In the English or the second price auctions, the first term will be equal to zero and only the second term remains, whereas in the first price or the Dutch auctions, the first term can be positive. Regardless of the first term, since the second term is strictly positive, the right produces a strictly higher joint profit. As in the previous example, when the buyers' values 


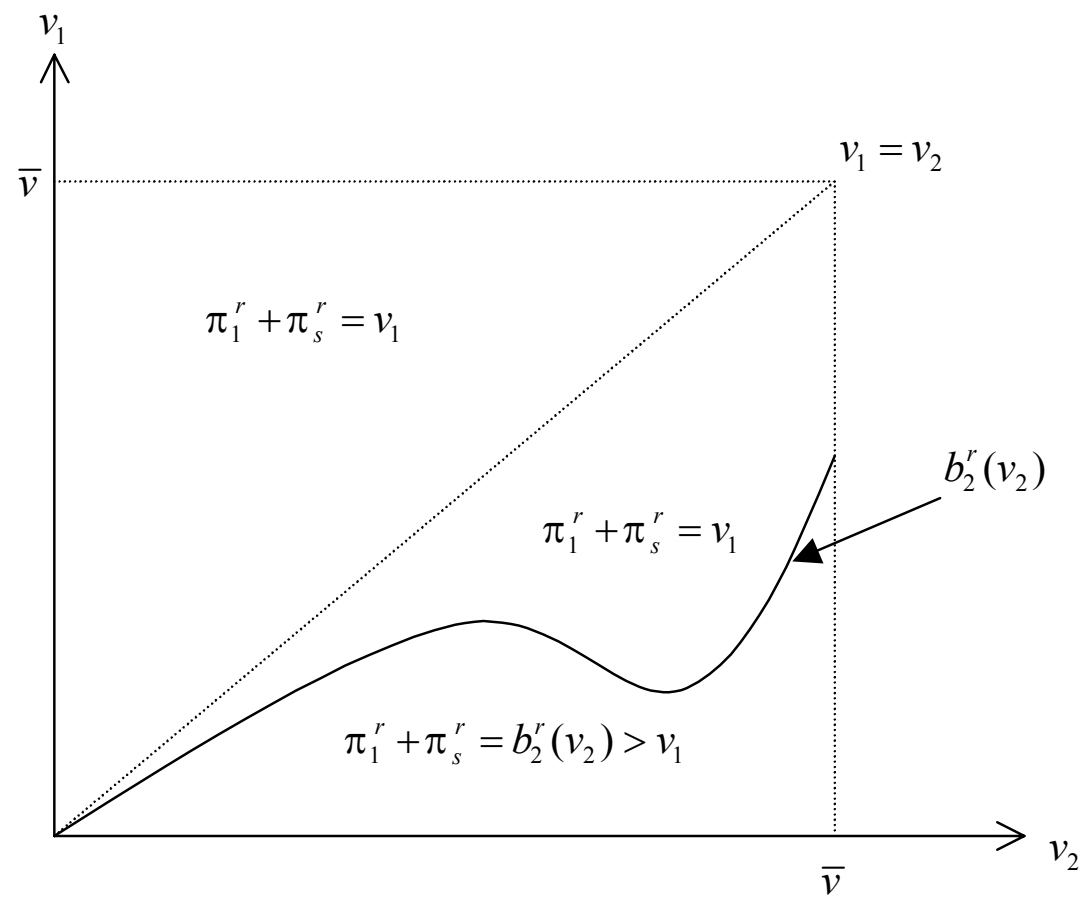

Figure 1: Impact of Right of First Refusal 
are uniformly and independently distributed, the first term disappears, and the second term simplifies to

$$
\int_{v_{2}=0}^{\bar{v}} \int_{v_{1}=0}^{v_{2} / 2}\left(\frac{v_{2}}{2}-v_{1}\right) \frac{1}{\bar{v}} \frac{1}{\bar{v}} d v_{1} d v_{2}=\frac{\bar{v}}{24}
$$

which is consistent with the result from the previous section.

\section{Conclusion}

This paper has made a first-cut analysis of the right of first refusal by showing how it can be used by the contracting parties to extract more rent from a non-contracting party. The right allows one of the bidders to observe the other bidder's bid, and therefore, to (most likely) increase both his chances of winning and his expected profit. The paper shows that compared to a more even-handed competition, while the other bidder is worse off, the joint profit of the right-holder and the seller will always be higher. In short, the argument falls under the larger theme of using a bilateral contract to exert an externality on a third party. Also consistent with the main arguments in the contractual externality literature, it is shown that the right, without any countervailing, welfare-producing features, will decrease social welfare. This is because the right allows the right-holder to win the auction even when his value of the good is lower than that of the competing bidder's.

The analysis can be easily extended to the settings of more than two bidders. It will be tantamount to seller's choosing only the highest offer $\left(b_{(1)}\right)$ among the competing bidders and presenting that to the right holder to match. This will reduce the extra rent accrued to the right-holder and the seller and increase welfare, since the probability that the highest bid is below the right-holder's value $\left(\operatorname{prob}\left(b_{(1)} \leq v_{1}\right)\right)$ decreases as the number of bidders increases. The paper can also easily incorporate a bilateral exchange of rights of first refusal. When two agents have either a joint or a shared ownership of a good, they can reciprocate the rights of first refusal to each other, as done in joint ventures or close corporations. One advantage of such exchange is that when the probabilities of separation are about equal, no other consideration may be necessary.

One policy implication from the analysis is that the arrangement should be of suspect when other, welfare-enhancing motivations are absent, and the courts should adopt a more stringent standard in its "reasonableness" test. However, it remains yet to be explored what some of these positive motivations could be. For instance, it could be possible that the right of first refusal can be used to provide a better (relationship-specific) investment incentives for the contracting parties, for instance, in joint ventures. Similarly, perhaps the right can be used to create a lock-in effect to foster better cooperation among the parties. While it is uncertain whether the right of first refusal is the optimal method of solving 
the investment or the cooperation problems, in the next step of the analysis, we intend to examine whether, or what, welfare-enhancing justifications exist, and how the courts can tailor their views toward the arrangement in light of the possible benefits. 


\section{Proofs}

The Standard Auctions. In the English auction, the dominant strategy is to stay in the auction as long as the announced price is less than one's value. Similarly, in the second-price-sealed-bid auction, it is each bidder's dominant strategy to bid his own value. Hence, the winning bidder pays the losing bidder's value, and the buyers' conditional profits can be written as

$$
E\left(\pi_{i} \mid v_{i}\right)=F_{j}\left(v_{i} \mid v_{i}\right)\left(v_{i}-\int_{v_{j}=0}^{v_{i}} v_{j} \frac{f\left(v_{j} \mid v_{i}\right)}{F_{j}\left(v_{i} \mid v_{i}\right)} d v_{j}\right)
$$

Let $b^{e}\left(v_{i}\right) \equiv \int_{v_{j}=0}^{v_{i}} v_{j} \frac{f\left(v_{j} \mid v_{i}\right)}{F_{j}\left(v_{i} \mid v_{i}\right)} d v_{j}$, which denotes the buyer's expected payment conditional on winning. Integrating over $v_{i}$, we get unconditional expected profits:

$$
E\left(\pi_{i}^{e}\right)=\int_{v_{i}=0}^{\bar{v}} \int_{v_{j}=0}^{v_{i}}\left(v_{i}-v_{j}\right) d F
$$

where $d F=f\left(v_{1}, v_{2}\right) d v_{j} d v_{i}$. Similarly, the seller's unconditional expected profit is

$$
E\left(\pi_{s}^{e}\right)=\int_{v_{1}=0}^{\bar{v}} \int_{v_{2}=0}^{v_{1}} v_{2} d F+\int_{v_{2}=0}^{\bar{v}} \int_{v_{1}=0}^{v_{2}} v_{1} d F .
$$

For the first price or the Dutch auctions, we can solve for a symmetric Bayesian Nash equilibrium as follows. First, given that the second buyer is using the strategy $b\left(v_{2}\right)$, which is strictly increasing and differentiable, the first buyer's expected profit if he bids $b_{1}$ when his value is $v_{1}$ is

$$
\pi_{1}\left(b_{1} \mid v_{1}\right)=p\left(b_{1}>b\left(v_{2}\right) \mid v_{1}\right)\left(v_{1}-b_{1}\right)=F_{2}\left(b^{-1}\left(b_{1}\right) \mid v_{1}\right)\left(v_{1}-b_{1}\right)
$$

The first order condition, after imposing symmetry, yields the differential equation of

$$
b^{\prime}\left(v_{1}\right)=\left(v_{1}-b\left(v_{1}\right)\right) \frac{f_{2}\left(v_{1} \mid v_{1}\right)}{F_{2}\left(v_{1} \mid v_{1}\right)} .
$$

When we solve the differential equation with $\mu\left(v_{1}\right)=\exp \left(-\int_{s=0}^{v_{1}} \frac{f_{2}(s \mid s)}{F_{2}(s \mid s)} d s\right)$ as the integrating factor and the boundary condition of $b(0)=0$, we get

$$
b^{f}\left(v_{1}\right)=\int_{v_{2}=0}^{v_{1}} v_{2} \exp \left(-\int_{s=v_{2}}^{v_{1}} \frac{f_{2}(s \mid s)}{F_{2}(s \mid s)} d s\right) \frac{f_{2}\left(v_{2} \mid v_{2}\right)}{F_{2}\left(v_{2} \mid v_{2}\right)} d v_{2}
$$

Next, we can show that the buyers' expected payments in the English or the second price auctions will be higher than in the Dutch or the first price auctions by showing that $b^{e}\left(v_{i}\right) \geq$ $b^{f}\left(v_{i}\right) \forall v_{i}$. First, $b^{e}(0)=b^{f}(0)=0$. Second,

$$
\frac{d b^{f}\left(v_{i}\right)}{d v_{i}}=\left(v_{i}-b^{f}\left(v_{i}\right)\right) \frac{f_{j}\left(v_{i} \mid v_{i}\right)}{F_{j}\left(v_{i} \mid v_{i}\right)}
$$


Third, after some algebra, it can be shown that

$$
\begin{aligned}
\frac{d b^{e}\left(v_{i}\right)}{d v_{i}}=\left(v_{i}-b^{e}\left(v_{i}\right)\right) \frac{f_{j}\left(v_{i} \mid v_{i}\right)}{F_{j}\left(v_{i} \mid v_{i}\right)} & \\
& +\int_{\alpha=0}^{v_{i}} \int_{\beta=0}^{v_{i}} \int_{\gamma=0}^{\alpha} \frac{f_{j}\left(\beta \mid v_{i}\right) f_{j}\left(\alpha \mid v_{i}\right)}{\left(F_{j}\left(v_{i} \mid v_{i}\right)\right)^{2}} \frac{\partial^{2} \ln f\left(v_{i}, \gamma\right)}{\partial v_{i} \partial \gamma} d \gamma d \beta d \alpha
\end{aligned}
$$

The monotone likelihood ratio property implies that the second term will be (weakly) positive $\forall v_{i}$. Also, whenever $b^{e}\left(v_{i}\right)<b^{f}\left(v_{i}\right), \frac{d b^{e}\left(v_{i}\right)}{d v_{i}}>\frac{d b^{f}\left(v_{i}\right)}{d v_{i}}$. Since both $b^{e}\left(v_{i}\right)$ and $b^{f}\left(v_{i}\right)$ are differentiable, $b^{e}\left(v_{i}\right) \geq b^{f}\left(v_{i}\right) \forall v_{i}$. Therefore, $E\left(\pi_{s}^{e}\right) \geq E\left(\pi_{s}^{f}\right)$ and $E\left(\pi_{i}^{e}\right) \leq E\left(\pi_{i}^{f}\right)$.

Proof of Lemma 1. Using the results from above,

$$
\begin{aligned}
E\left(\pi_{s}^{e}\right)+E\left(\pi_{1}^{e}\right) & =\int_{v_{1}=0}^{\bar{v}} \int_{v_{2}=0}^{v_{1}} v_{2} d F+\int_{v_{2}=0}^{\bar{v}} \int_{v_{1}=0}^{v_{2}} v_{1} d F+\int_{v_{1}=0}^{\bar{v}} \int_{v_{2}=0}^{v_{1}}\left(v_{1}-v_{2}\right) d F \\
& =\int_{v_{1}=0}^{\bar{v}} \int_{v_{2}=0}^{\bar{v}} v_{1} d F=E\left(v_{1}\right)
\end{aligned}
$$

Furthermore, since the second buyer pays (weakly) less in the first price auction than in the English auction,

$$
\begin{aligned}
E\left(\pi_{s}^{f}\right)+E\left(\pi_{1}^{f}\right) & =\int_{v_{1}=0}^{\bar{v}} \int_{v_{2}=0}^{v_{1}} v_{1} d F+\int_{v_{2}=0}^{\bar{v}} \int_{v_{1}=0}^{v_{2}} b^{f}\left(v_{2}\right) d F \\
& \leq E\left(\pi_{s}^{e}\right)+E\left(\pi_{1}^{e}\right)
\end{aligned}
$$

Proof of Lemma 2. Conditional on $v_{2}, B_{2}$ maximizes

$$
\pi_{2}\left(b_{2} \mid v_{2}\right)=p\left(b_{2}>v_{1} \mid v_{2}\right)\left(v_{2}-b_{2}\right)=F_{1}\left(b_{2} \mid v_{2}\right)\left(v_{2}-b_{2}\right) .
$$

The first order condition is

$$
\frac{d \pi_{2}\left(b_{2} \mid v_{2}\right)}{d b_{2}}=-F_{1}\left(b_{2} \mid v_{2}\right)+\left(v_{2}-b_{2}\right) f_{1}\left(b_{2} \mid v_{2}\right)=0
$$

so that

$$
b_{2}^{r}\left(v_{2}\right)=v_{2}-\frac{F_{1}\left(b_{2}^{r}\left(v_{2}\right) \mid v_{2}\right)}{f_{1}\left(b_{2}^{r}\left(v_{2}\right) \mid v_{2}\right)}
$$


Since $f\left(v_{1}, v_{2}\right)>0 \forall\left(v_{1}, v_{2}\right), f_{1}\left(b_{2}^{r}\left(v_{2}\right) \mid v_{2}\right)>0 \forall v_{2}$, so that $b_{2}^{r}\left(v_{2}\right)<v_{2}$ unless $v_{2}=0$.

Proof of Proposition 1. With the right of first refusal, the buyers' unconditional expected profits are

$$
E\left(\pi_{2}^{r}\right)=\int_{v_{2}=0}^{\bar{v}} \int_{v_{1}=0}^{b_{2}^{r}\left(v_{2}\right)}\left(v_{2}-b_{2}^{r}\left(v_{2}\right)\right) d F
$$

and

$$
E\left(\pi_{1}^{r}\right)=\int_{v_{2}=0}^{\bar{v}} \int_{v_{1}=b_{2}^{r}\left(v_{2}\right)}^{\bar{v}}\left(v_{1}-b_{2}^{r}\left(v_{2}\right)\right) d F
$$

Recall that under the English or the second price auctions,

$$
E\left(\pi_{i}^{e}\right)=\int_{v_{i}=0}^{\bar{v}} \int_{v_{j}=0}^{v_{i}}\left(v_{i}-v_{j}\right) d F
$$

Since $b_{2}^{r}\left(v_{2}\right)<v_{2}$ and $v_{1} \leq b_{2}^{r}\left(v_{2}\right)$ when the second buyer wins, $E\left(\pi_{2}^{r}\right)<E\left(\pi_{2}^{e}\right)$ and $E\left(\pi_{1}^{r}\right)>E\left(\pi_{1}^{e}\right)$. With the first price or the Dutch auctions, $E\left(\pi_{2}^{r}\right)<E\left(\pi_{2}^{e}\right) \leq E\left(\pi_{2}^{f}\right)$. For the first buyer, however, $E\left(\pi_{1}^{r}\right) \gtreqless E\left(\pi_{1}^{f}\right)$. Suppose $E\left(\pi_{1}^{e}\right)<E\left(\pi_{1}^{f}\right)$. Then, $b_{2}^{r}\left(v_{2}\right) \rightarrow v_{2}$ implies that $E\left(\pi_{1}^{r}\right) \rightarrow E\left(\pi_{1}^{e}\right)$ so that, in the limit, $E\left(\pi_{1}^{r}\right)<E\left(\pi_{1}^{f}\right)$. On the other hand, as $b_{2}^{r}\left(v_{2}\right) \rightarrow 0$, the first buyer wins all the time with almost zero bid, so that $E\left(\pi_{1}^{r}\right) \rightarrow E\left(v_{1}\right)$, which is strictly higher than $E\left(\pi_{1}^{f}\right)$.

Proof of Proposition 2. With the right of first refusal, the seller's expected profit is

$$
\begin{aligned}
E\left(\pi_{s}^{r}\right) & =\int_{v_{2}=0}^{\bar{v}} \int_{v_{1}=0}^{b_{2}^{r}\left(v_{2}\right)} b_{2}^{r}\left(v_{2}\right) d F+\int_{v_{2}=0}^{\bar{v}} \int_{v_{1}=b_{2}^{r}\left(v_{2}\right)}^{\bar{v}} b_{2}^{r}\left(v_{2}\right) d F \\
& =E\left(b_{2}^{r}\left(v_{2}\right)\right)
\end{aligned}
$$

which can also be written as

$$
E\left(\pi_{s}^{r}\right)=\int_{v_{1}=0}^{\bar{v}} \int_{v_{2}=0}^{v_{1}} b_{2}^{r}\left(v_{2}\right) d F+\int_{v_{2}=0}^{\bar{v}} \int_{v_{1}=0}^{v_{2}} b_{2}^{r}\left(v_{2}\right) d F
$$

Recall that under the English auction,

$$
E\left(\pi_{s}^{e}\right)=\int_{v_{1}=0}^{\bar{v}} \int_{v_{2}=0}^{v_{1}} v_{2} d F+\int_{v_{2}=0}^{\bar{v}} \int_{v_{1}=0}^{v_{2}} v_{1} d F
$$


Since $b_{2}^{r}\left(v_{2}\right)<v_{2}$,

$$
\int_{v_{1}=0}^{\bar{v}} \int_{v_{2}=0}^{v_{1}} v_{2} d F>\int_{v_{1}=0}^{\bar{v}} \int_{v_{2}=0}^{v_{1}} b_{2}^{r}\left(v_{2}\right) d F
$$

but

$$
\int_{v_{2}=0}^{\bar{v}} \int_{v_{1}=0}^{v_{2}} v_{1} d F \gtreqless \int_{v_{2}=0}^{\bar{v}} \int_{v_{1}=0}^{v_{2}} b_{2}^{r}\left(v_{2}\right) d F,
$$

so that the relative sizes of $E\left(\pi_{s}^{r}\right)$ and $E\left(\pi_{s}^{e}\right)$ are ambiguous. As $b_{2}^{r}\left(v_{2}\right) \rightarrow v_{2}$,

$$
\int_{v_{1}=0}^{\bar{v}} \int_{v_{2}=0}^{v_{1}} b_{2}^{r}\left(v_{2}\right) d F \rightarrow \int_{v_{1}=0}^{\bar{v}} \int_{v_{2}=0}^{v_{1}} v_{2} d F
$$

and

$$
\int_{v_{2}=0}^{\bar{v}} \int_{v_{1}=0}^{v_{2}} b_{2}^{r}\left(v_{2}\right) d F>\int_{v_{2}=0}^{\bar{v}} \int_{v_{1}=0}^{v_{2}} v_{1} d F
$$

so that $E\left(\pi_{s}^{e}\right)<E\left(\pi_{s}^{r}\right)$. As $b_{2}^{r}\left(v_{2}\right) \rightarrow 0$, on the other hand, $E\left(\pi_{s}^{e}\right)>E\left(\pi_{s}^{r}\right)$.

Proof of Proposition 3. Recall that

$$
E\left(\pi_{s}^{f}\right)+E\left(\pi_{1}^{f}\right) \leq E\left(\pi_{s}^{e}\right)+E\left(\pi_{1}^{e}\right)=\int_{v_{1}=0}^{\bar{v}} v_{1} d F
$$

With the right of first refusal,

$$
\begin{aligned}
E\left(\pi_{1}^{r}\right)+E\left(\pi_{s}^{r}\right) & =\int_{v_{2}=0}^{\bar{v}} \int_{v_{1}=b_{2}^{r}\left(v_{2}\right)}^{\bar{v}}\left(v_{1}-b_{2}^{r}\left(v_{2}\right)\right) d F+\int_{v_{2}=0}^{\bar{v}} \int_{v_{1}=0}^{b_{2}^{r}\left(v_{2}\right)} b_{2}^{r}\left(v_{2}\right) d F+\int_{v_{2}=0}^{\bar{v}} \int_{v_{1}=b_{2}^{r}\left(v_{2}\right)}^{\bar{v}} b_{2}^{r}\left(v_{2}\right) d F \\
& =\int_{v_{2}=0}^{\bar{v}} \int_{v_{1}=b_{2}^{r}\left(v_{2}\right)}^{\bar{v}} v_{1} d F+\int_{v_{2}=0}^{\bar{v}} \int_{v_{1}=0}^{b_{2}^{r}\left(v_{2}\right)} b_{2}^{r}\left(v_{2}\right) d F
\end{aligned}
$$

Hence,

$$
\left\{E\left(\pi_{1}^{r}\right)+E\left(\pi_{s}^{r}\right)\right\}-\left\{E\left(\pi_{s}^{e}\right)+E\left(\pi_{1}^{e}\right)\right\}=\int_{v_{2}=0}^{\bar{v}} \int_{v_{1}=0}^{b_{2}^{r}\left(v_{2}\right)}\left(b_{2}^{r}\left(v_{2}\right)-v_{1}\right) d F>0
$$




\section{References}

[1] Aghion, P. and Bolton, P. (1987), "Contracts as a Barrier to Entry," American Economic Review 77, 388-401.

[2] Bainbridge, S. M. (2002), Corporation Law and Economics, Foundation Press, New York, New York.

[3] Choper, J., Coffee, J. and Gilson, R. (2000), Cases and Materials on Corporations, 5th edition, Aspen Publishers, New York, New York.

[4] Corbin, A. L. (1963), Corbin on Contracts: A Comprehensive Treatise on the Working Rules of Contract Law, West Publishing, St. Paul, Minnesota.

[5] Cremer, J. and McLean, R. P. (1988), "Full Extraction of the Surplus in Bayesian and Dominant Strategy Auctions," Econometrica 56, 1247-57.

[6] Easterbrook, F. H. and Fischel, D. R. (1986), "Close Corporations and Agency Costs," Stanford Law Review 38, 271-301.

[7] Easterbrook, F. H. and Fischel, D. R. (1991), The Economic Structure of Corporate Law, Harvard University Press, Cambridge, Massachusetts.

[8] Graham, D. A. and Marshall, R. C. (1987), "Collusive Bidder Behavior at Single-Object Second-Price and English Auctions," Journal of Political Economy 95, 1217-39.

[9] Hendricks, K. and Porter, R. H. (1989), "Collusion in Auctions," Annales D'Economie et de Statistique 15/16, 217-30.

[10] Johnson, C. D. and Stanford, D. J. (1999), "Rights of First Refusal in Oil and Gas Transactions: A Progressive Analysis," Alberta Law Review 37, 316-51.

[11] Klemperer, P. (1999), "Auction Theory: A Guide to the Literature," Journal of Economic Surveys 13(3), 227-86.

[12] Levin, D. and Smith, J. L. (1996), "Optimal Reservation Prices in Auctions," Economic Journal 106, 1271-83.

[13] Mailath, G. J. and Zemsky, P. (1991), "Collusion in Second Price Auctions with Heterogeneous Bidders," Games and Economic Behavior 3, 467-86.

[14] Maskin, E. S. and Riley, J. G. (1985), "Auction Theory with Private Values," American Economic Review Papers and Proceedings 75, 150-55.

[15] McAfee, R. P. and McMillan, J. (1987), "Auctions and Bidding," Journal of Economic Literature 25, 669-738. 
[16] McAfee, R. P. and McMillan, J. (1992), "Bidding Rings," American Economic Review 82, 579-99.

[17] Milgrom, P. R. and Weber, R. J. (1982), "A Theory of Auctions and Competitive Bidding," Econometrica 50, 1089-1122.

[18] Myerson, R. (1981), "Optimal Auction Design," Mathematics of Operations Research $6,58-73$.

[19] Riley, J. G. and Samuelson, W. F. (1981), "Optimal Auctions," American Economic Review 71, 381-92.

[20] Robinson, M. S. (1985), "Collusion and the Choice of Auctions," Rand Journal of Economics 16, 141-45.

[21] Smith, J. L. (1981), "Non-Aggressive Bidding Behavior and the 'Winner's Curse'," Economic Inquiry 19, 380-88.

[22] Walker, D. I. (1999), "Rethinking Rights of First Refusal," Stanford Journal of Law, Business \& Finance 5, 1-58. 


\section{Notes}

${ }^{1}$ Walker argues that the right is being used to "inhibit [the seller] from selling in the first place." Walker (1999) at 6. Similar argument is also made by the highest New York state court in LIN Broadcasting v. Metromedia Inc., 74 N.Y.2d 54, 62. If this is indeed a case, however, it remains a puzzle as to why the seller would voluntarily agree to the right.

${ }^{2}$ See Walker (1999) at 7-14 for an overview of the practice. Johnson and Stanford (1999) has an extensive treatment of the right used in oil and gas transactions.

${ }^{3}$ See Bainbridge (2002) at 811. See also Easterbrook and Fischel (1991) at 238-43.

${ }^{4}$ Allen v. Biltmore Tissue Corp., 2 N.Y.2d 534 (1957), discussing Massachusetts close corporations law. See also $1 \mathrm{~A}$ Corbin on Contracts $\S 261$, at 468-82 (1963).

${ }^{5}$ Others have studied collusive arrangements among bidders. See, e.g., Graham and Marshall (1987) and McAfee and McMillan (1992).

${ }^{6}$ This argument was formalized in Aghion and Bolton (1987). Their result was on liquidated damages, whereas ours is on auction design, but the substance of the argument is similar.

${ }^{7}$ For the possibility that the right holder's value may be sensitive to the identify of the winner, we can introduce an asymmetry by letting $v_{1} \in\left[\underline{v}_{1}, \bar{v}_{1}\right]$ and $v_{2} \in\left[\underline{v}_{2}, \bar{v}_{2}\right]$ where $0 \leq \underline{v}_{1}<\bar{v}_{2}$ and $\bar{v}_{1}>\bar{v}_{2}$. We can further decompose $v_{1}$ to be $v_{11}-v_{12}$, where $v_{11}$ is the right-holder's value when he wins the auction and $v_{12}$ is his value when the rival wins. While these generalizations can produce correlation in values with asymmetric ranges of support, the main results will remain unaffected.

${ }^{8}$ Milgrom and Weber (1982) calls this relation "affiliation" when the density function is not differentiable. In that case, MLRP is stated as: $\frac{f\left(x^{\prime} \mid y^{\prime}\right)}{f\left(x \mid y^{\prime}\right)} \geq \frac{f\left(x^{\prime} \mid y\right)}{f(x \mid y)} \forall x^{\prime} \geq x$ and $y^{\prime} \geq y$.

${ }^{9}$ Although the interdependence assumption can allow the seller to extract the entire surplus from the bidders, as in Cremer and McLean (1988), since such mechanisms impose large, negative profits on the bidders and seem unrealistic, we focus only on the standard auctions.

${ }^{10}$ Since the seller is negotiating this right before $B_{1}$ discovers $v_{1}$, the negotiation does not involve asymmetric information. Also, instead of negotiating with $B_{1}$, the seller can, in theory, put up the right for auction between the buyers and/or set a reservation price to extract more surplus. However, in reality, since the identity of $B_{2}$ is usually unknown until he makes a bid for the property, such mechanisms will be difficult to implement.

${ }^{11}$ Allowing for the uncertainty in the buyers' values, where the buyers observe only the signals (e.g., $\left.s_{1}=v_{1}+\varepsilon_{1}\right)$ about the values of the property, will not change the main results. 